\title{
PETROGRAFIA, GEOQUÍMICA E GEOCRONOLOGIA DO LEUCOGRANITO PERALUMINOSO DO COMPLEXO DE GOUVEIA-MG
}

\author{
Alexandre de Oliveira Chaves ${ }^{1}$, Raphael Martins Coelho ${ }^{1}$ \\ ${ }^{1}$ Departamento de Geologia - Instituto de Geociências - Universidade Federal de Minas Gerais (IGC-UFMG).alochaves@yahoo.com.br; \\ raphaelmcoelho@yahoo.com.br
}

Recebido em 7 de agosto de 2013; aceito em 27 de dezembro de 2013

\begin{abstract}
RESUMO - As características petrográficas e geoquímicas do leucogranito peraluminoso do Complexo de Gouveia (MG), sua relação geológica a migmatitos deste complexo arqueano e a zonas de cisalhamento, bem como sua intensa milonitização, aproximam sua gênese à dos granitos de ambiente de colisão continental ou da tectônica transcorrente a ela associada. Idades químicas U-Th-Pb em cristais homogêneos de monazita inclusos em K-feldspato do leucogranito mostram valor médio em torno de $1811+/-32 \mathrm{Ma}$, que marca a cristalização do magma leucogranítico derivado da anatexia dos migmatitos. Esta anatexia teria se dado em ambiente hidratado e em condições de alto grau metamórfico (fácies anfibolito alto) atingidas em função do espessamento crustal e cisalhamentos regionais relacionados às fases sin- a tardi-colisionais do evento Transamazônico. Além disso, esta rocha foi submetida ao retrabalhamento Brasiliano sob fácies xisto-verde, identificado pela cloritização da biotita e da granada e por processos de turmalinização. A monazita associada aos corpos tardios de turmalinitos apresenta idade química U-Th-Pb de 634 +/- 20 Ma.
\end{abstract}

Palavras-chave: LEUCOGRANITO PERALUMINOSO, GOUVEIA, TECTÔNICA COLISIONAL, TRANSAMAZÔNICO, BRASILIANO.

ABSTRACT - The petrographic and geochemical characteristics of the peraluminous leucogranite of the Gouveia Complex (MG), their association to migmatites of such archean complex and to shear zones and their intense mylonitization approach their genesis to the granites of continental collision setting or linked transcurrent tectonics. U-Th-Pb chemical ages of Omonazite grains included in K-feldspar of the leucogranite show mean values around $1811+/-32 \mathrm{Ma}$, which reveal its magmatic crystallization from anatexis of the migmatites. The anatexis that generated the leucogranites has been given in hydrated environment and high-grade metamorphic conditions (amphibolite facies) reached during crustal thickening and regional shear related to the syn- to late-collisional phases of the Transamazonian event. However, this rock has been subjected to Brasiliano reworking under green-schist facies, identified by chloritization of biotite and garnet and by tourmalinization processes. Monazite associated with late tourmalinite bodies has $\mathrm{U}-\mathrm{Th}-\mathrm{Pb}$ chemical age of $634+/-20 \mathrm{Ma}$.

Keywords: PERALUMINOUS LEUCOGRANITE, GOUVEIA, COLLISIONAL TECTONICS, TRANSAMAZONIAN, BRASILIANO.

\section{INTRODUÇÃO}

Depois de 30 anos, desde os trabalhos pioneiros de Hoffmann (1983), o leucogranito porfirítico peraluminoso do Complexo de Gouveia (MG) volta a ser alvo de estudos em função da recente verificação, pelos autores deste trabalho, da existência de assembléia mineral específica e de características geoquímicas e geocronológicas peculiares que o correlaciona a uma ambiência tectônica colisional. Portanto, o objetivo do presente trabalho é apresentar a geologia e os dados petrográficos, litogeoquímicos e geocronológicos (datação química U-Th-Pb da monazita) deste litotipo como suporte às implicações petrológicas e tectônicas a ele relacionadas.

\section{GEOLOGIA REGIONAL}

A área investigada encontra-se na chamada depressão de Gouveia, uma janela estrutural do embasamento cristalino embutida na Serra do Espinhaço Meridional, em Minas Gerais (Figura 1). A principal unidade litoestratigráfica que sustenta o espigão de serras é o Supergrupo Espinhaço, depositado a partir do final do Paleoproterozóico $(\sim 1,7 \mathrm{Ga})$, constituído principalmente por quartzitos com intercalações de filitos e metaconglomerados, com raras intrusões de rochas metavulcânicas em sua porção basal (Schöll \& Fogaça, 1979; Machado et al., 1989). No Espinhaço Meridional, o Supergrupo
Espinhaço é sobreposto por metassedimentos do Supergrupo São Francisco, do Neoproterozóico (0,85-0,6 Ga), integrado pelos grupos Macaúbas e Bambuí, o último aflorando exclusivamente a oeste da serra. Em termos geotectônicos, essas megassequências integram a Faixa de Dobramentos Araçuaí, que margeia o Craton São Francisco (CSF) a leste. A Orogenia Araçuaí desenvolveu-se durante o Ciclo Brasiliano entre 630 e 490 Ma (Uhlein, 1991; Pedrosa-Soares et al., 2001), gerando na Serra do Espinhaço grandes dobramentos de eixos norte-sul com assimetria em direção ao CSF e foliações planoaxiais a tais dobramentos, com mergulhos altos para leste. O metamorfismo superimposto varia da fácies xisto-verde a anfibolito, de oeste para leste.

Rochas da infra-estrutura ocorrem na porção central serrana (região de Gouveia) e na margem leste da mesma (Figura 1). O Complexo de Gouveia, segundo Noce et al. (2007), constitui o embasamento do Orógeno Araçuaí juntamente com os complexos Guanhães, Porteirinha, Mantiqueira e Juiz de Fora (Figura 2). Eles possuem caráter autóctone a para-autóctone. Estes complexos são formados essencialmente por granitos, gnaisses orto e paraderivados e migmatitos TTG (tonalitotrondhjemito-granodiorito).

O Complexo de Gouveia é constituído essencialmente por uma massa de leucogranito peraluminoso anatético, muitas vezes porfirítico, 
com fenocristais centimétricos de feldspato (Hoffmann, 1983). Este leucogranito é facilmente distinguido de suas rochas encaixantes em imagem gamaespectrométrica (Figura 3) por ser mais rico em $\mathrm{U}$, Th e $\mathrm{K}$ que as mesmas. Eventualmente são encontrados restos de migmatitos paraderivados no seu interior em contato transicional difuso. Machado et al. (1989) encontraram idades U-Pb em zircão de 1844 +/- 15 Ma e 2839 +/- 14 Ma para o leucogranito. Durante ou após sua intrusão, estes granitóides foram localmente deformados ao longo de extensas zonas de cisalhamento subverticais (Hoffmann, 1983). Turmalinitos tardios locais, ricos em quartzo e sericita, aparecem cruzando o leucogranito ao longo das zonas de cisalhamento e guardam clastos de quartzito.

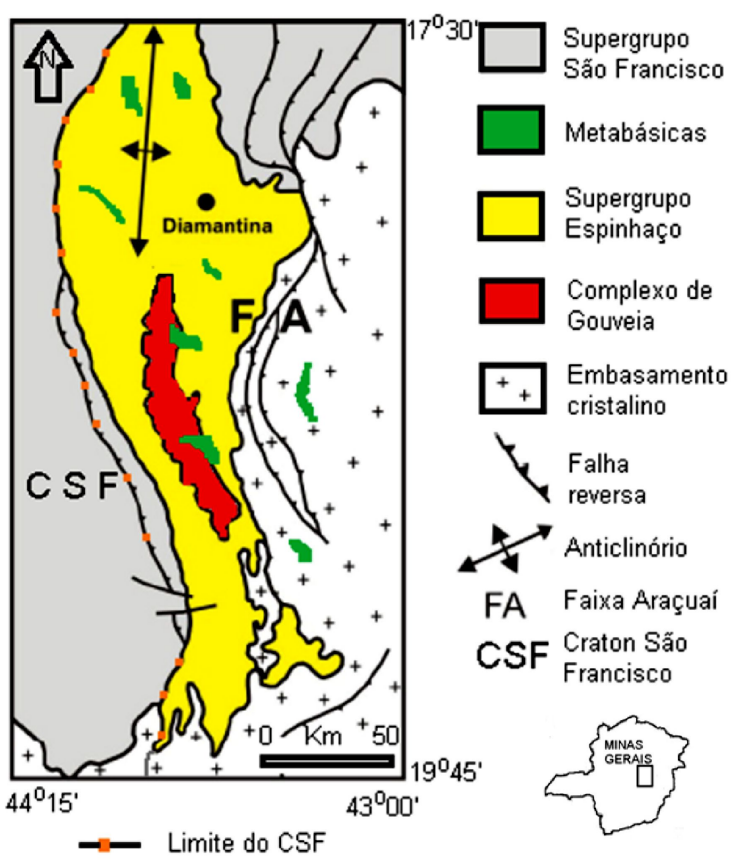

Figura 1 - Arcabouço geológico regional, com destaque ao Complexo de Gouveia. Modificado de Pedrosa-Soares e SoaresFilho (1997).

Segundo Cruz et al. (2005), a deformação no embasamento de Gouveia ocorreu por meio da nucleação de zonas de cisalhamento dúctil-rúpteis de direção geral N-S. Tais zonas são constituídas por uma associação de rochas miloníticas e filoníticas com mergulhos subverticais, diferentemente da sua continuação na cobertura. Indicadores cinemáticos de vários tipos revelam duas fases principais de deformação. A primeira, com cinemática transcorrente sinistral e componente reverso, foi responsável pela nucleação das zonas de cisalhamento. A segunda, com cinemática apontando movimentação para oeste, desenvolveuse por meio da reativação das zonas anteriormente nucleadas.
Metadiabásios cortam o leucogranito de Gouveia e todos os litotipos supracitados, com exceção daqueles pertencentes ao Supergrupo São Francisco. A idade dessas rochas é de $906 \mathrm{Ma}$ (Machado et al., 1989), porém foram metamorfisadas no fácies xistoverde durante o evento tectonotermal Brasiliano (Dossin et al., 1993).

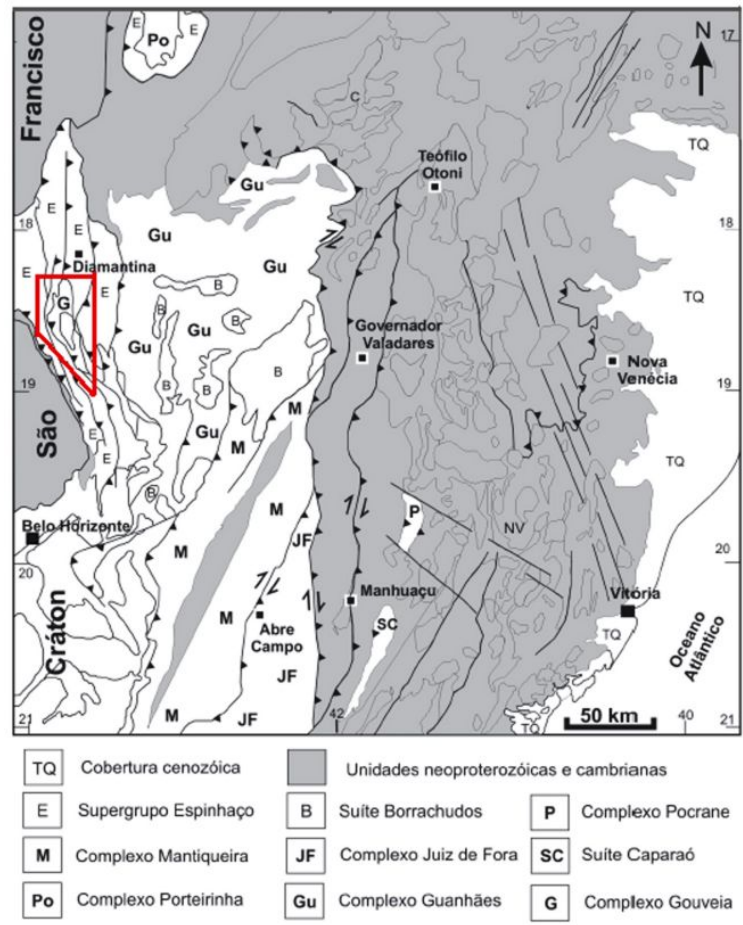

Figura 2 - O Orógeno Araçuaí e seus complexos de embasamento (Noce et al., 2007). Em destaque, o Complexo de Gouveia.

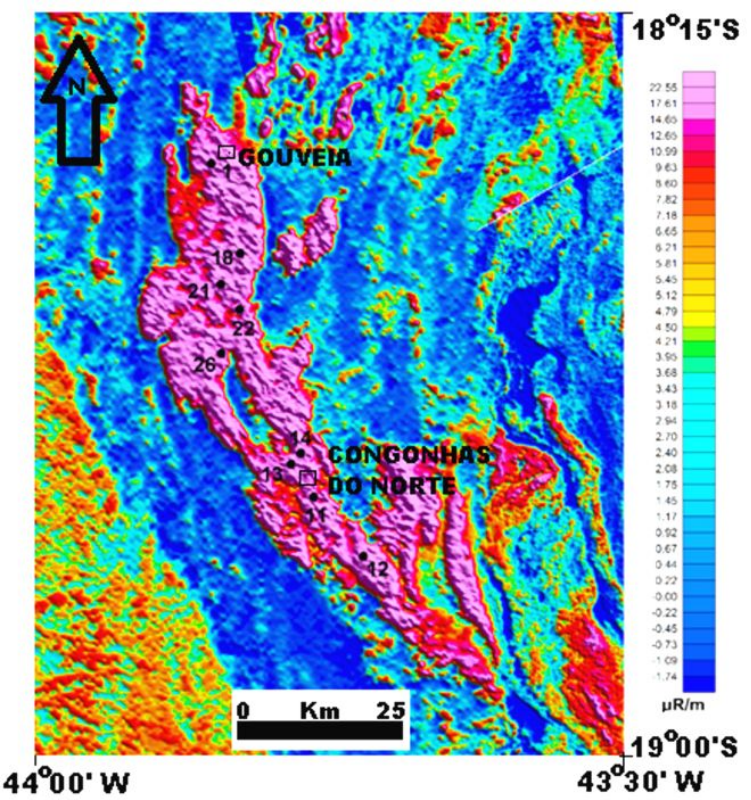

Figura 3 - Imagem gamaespectrométrica - contagem total U-ThK(CODEMIG, 2012). O leucogranito de Gouveia, mais rico em $U, T h$ e $K$ que as rochas circundantes, aparece em rosa. Dosagem de radiação gama em microRoentgen/minuto $(\mu R / m)$. Os pontos amostrados estão apresentados na imagem. 


\section{METODOLOGIA}

Foram coletadas 9 amostras de rocha granítica leucocrática nos arredores das localidades de Gouveia, Pedro Pereira e Congonhas do Norte (MG), todas no interior do Complexo de Gouveia (Figura 3). Nos laboratórios do Centro de Pesquisas Manoel Teixeira da Costa (IGC/UFMG), foram feitas lâminas delgadas polidas das amostras, as quais foram utilizadas nos estudos micropetrográficos em microscópio polarizador. Após sua pulverização em moinho de panela, as amostras foram enviadas ao Laboratório SGS-Geosol. Ali, os elementos maiores e cinco elementos traços ( $\mathrm{Ba}, \mathrm{Nb}, \mathrm{Sr}, \mathrm{Y}, \mathrm{Zr}$ ) foram analisados por ICP-OES e sete outros traços (Rb, Ta, $\mathrm{Sn}, \mathrm{Hf}, \mathrm{Ni}, \mathrm{Th}, \mathrm{U})$ em conjunto com quatorze elementos terras-raras, foram analisados por ICPMS. A perda ao fogo ocorreu por diferença de peso após aquecimento a $1000^{\circ} \mathrm{C}$.

Para fins geocronológicos, utilizando as próprias lâminas delgadas e o método de datação química UTh- $\mathrm{Pb}$, as composições químicas das monazitas das amostras 1, 11, 14, 22 e 26 foram obtidas no Laboratório de Microanálises do Departamento de Física da UFMG, em uma microssonda JEOL, modelo JXA-8900, através de espectrometria por dispersão de comprimento de onda (WDS). O imageamento das monazitas foi realizado pela técnica de elétrons retro-espalhados nesta microssonda.

As condições de medidas e padrões analíticos empregados encontram-se na tabela 1 . Sobreposições de picos de raios- $\mathrm{X}$ entre $\mathrm{Y}$ e $\mathrm{Pb}$ não precisaram ser corrigidas por não ter havido medição em PbMa (Chumbo M alfa), mas apenas em $\mathrm{PbMb}$ (chumbo $\mathrm{M}$ beta). Entretanto, para se evitar erros nas idades obtidas, a interferência de ThMz (tório $\mathrm{M}$ gama) sobre o UMb (urânio $\mathrm{M}$ beta) medido precisou ser corrigida, seguindo Scherrer et al. (2000) em adaptação às condições do LMAUFMG, da seguinte maneira:

$U$ corrigido $=U$ medido $-(0.006365 \times$ Th medido $)$.

$\mathrm{O}$ cálculo das idades químicas U-Th-Pb foi realizado com o auxílio do software EPMA Dating (Pommier et al., 2004), enquanto que o cálculo das médias das idades e de seus parâmetros estatísticos foi obtido com o apoio do software Isoplot (Ludwig, 2003).

\section{PETROGRAFIA DO LEUCOGRANITO}

Levantamentos de campo confirmam que a maior parte do Complexo de Gouveia é constituída por massas do leucogranito investigado. Macroscopicamente, as amostras estudadas são leucocráticas esbranquiçadas, inequigranulares, têm granulação grossa a muito grossa, sendo geralmente porfiríticas com fenocristais de K-feldspato atingindo $5 \mathrm{~cm}$ ou mais. Entretanto, apresentam-se foliadas, tendo sido submetidas a processos metamórficos. Possuem bolsões mili a centimétricos de material esverdeado rico em clorita, sendo bordejados por um halo amarelado. Em algumas amostras é possível observar que, no interior deste material verde, geralmente há granada de cor vermelha (figura 4A).

Tabela 1 - Condições de medidas e padrões analíticos empregados na investigação quantitativa dos elementos presentes em monazitas pela microssonda eletrônica do LMA-UFMG. Os padrões Monazita, Rodonita, Hematita e Crocoita são da Coleção Astimex. Os padrões YAG, Apatita e Thorita, são da Coleção lan Steele. Os ortofostatos de terras raras são doação do Smithsonian Institute.

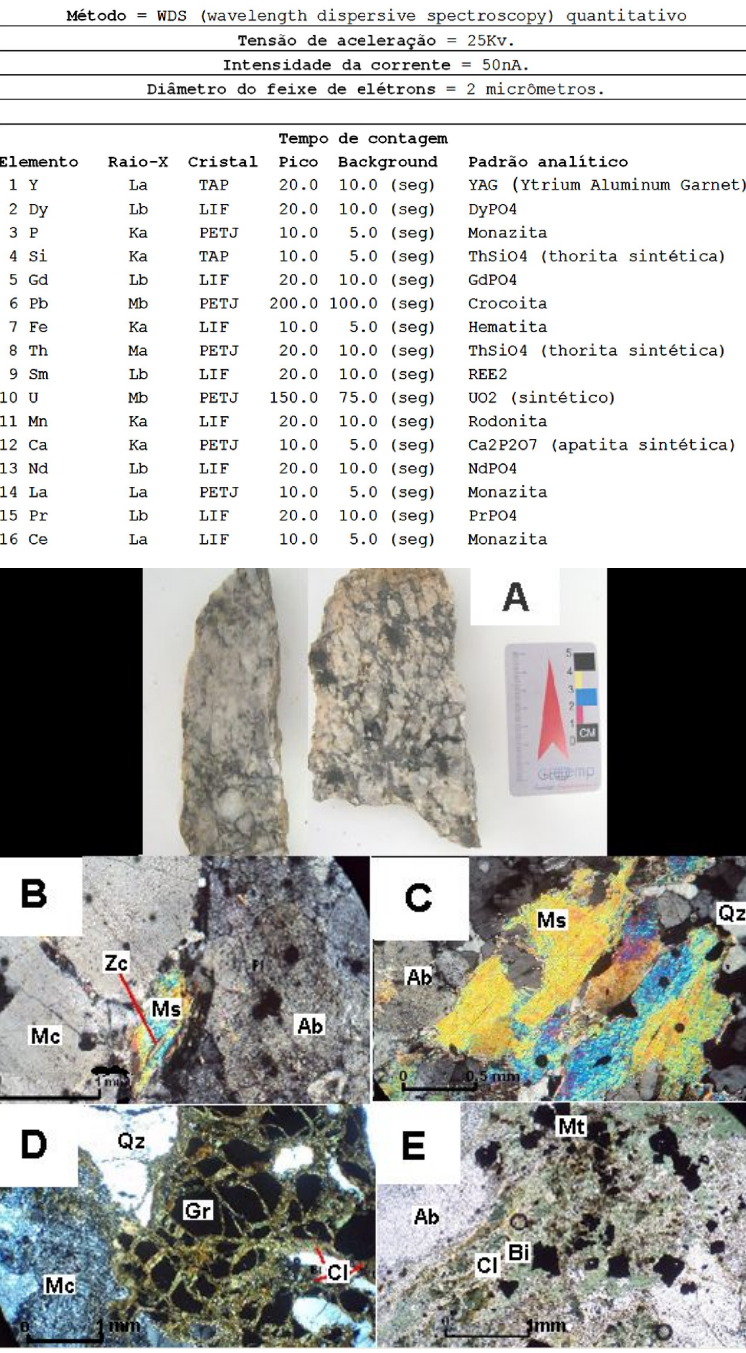

Figura 4 - A - Amostras de mão representativas do granito estudado. B - Aspecto dos feldspatos em fotomicrografia de luz

polarizada. C-Quartzo recristalizado e muscovita em

fotomicrografia de luz polarizada. D-Granada almandina isotrópica (preto) em fotomicrografia de luz polarizada. E-Biotita cloritizada e magnetita em fotomicrografia sob nicóis descruzados. Abreviações: Mc - microclina, Ab-albita, Zczircão, Ms - muscovita, Qz-quartzo, Gr-granada, Bi-biotita, Cl - clorita, Mt-magnetita. 
Microscopicamente, o leucogranito é holocristalino e hipidiomórfico. O feldspato potássico, que ocorre em maior quantidade, apresenta textura micro a macropertítica, sendo caracterizado como microclina a partir da geminação tartan. A textura poiquilítica está localmente preservada e ele engloba cristais de plagioclásio. Processos intempéricos sobre o K-feldspato resultaram no surgimento de argilominerais (illita). O plagioclásio albítico, saussuritizado, se apresenta também na matriz (figura 4B). Os cristais de quartzo estão recristalizados e com extinção ondulante, com o contato entre os grãos fazendo ângulos de $120^{\circ}$ entre si (figura 4C). A granada, do tipo almandina, ocorre geralmente fraturada e substituída por clorita (figura 4D). A biotita e muscovita estão presentes e caracterizam a rocha como um granito a duas micas. A muscovita (figura 4C) é mais abundante que a biotita e ambas mostram tanto feições ígneas quanto metamórficas. Às vezes ocorrem como placas maiores e corroídas nas bordas e às vezes como pequenas plaquetas orientadas na foliação. A maior parte dos cristais de biotita acha-se cloritizada (figura 4E). Dentre os opacos ocorrem a ilmenita leucoxenizada e magnetita. Como mineralogia acessória, aparece turmalina e raros cristais de zircão, allanita e monazita.

No diagrama modal QAP (Figura 5A), o leucogranito de Gouveia é classificado como álcalifeldspato granito.

Tabela 2 - Tabela 2:Composições químicas das amostras do leucogranito de Gouveia (Fe total expresso como FeOT)

\begin{tabular}{|c|c|c|c|c|c|c|c|c|c|}
\hline Amostra & 1 & 11 & 12 & 13 & 14 & 18 & 21 & 22 & 26 \\
\hline \multicolumn{10}{|c|}{ Elem. maiores } \\
\hline $\mathrm{SiO2}$ & 71.59 & 70.40 & 73.09 & 72.96 & 69.75 & 71.59 & 77.02 & 71.59 & 73.01 \\
\hline TiO2 & 0.25 & 0.10 & 0.14 & 0.14 & 0.10 & 0.14 & 0.05 & 0.15 & 0.13 \\
\hline Al2O3 & 14.95 & 15.36 & 15.10 & 15.46 & 15.30 & 13.83 & 13.07 & 14.09 & 15.21 \\
\hline $\mathrm{FeOT}$ & 1.97 & 1.25 & 1.34 & 1.65 & 1.56 & 1.82 & 0.62 & 1.80 & 1.63 \\
\hline $\mathrm{CaO}$ & 0.62 & 0.26 & 0.55 & 0.65 & 0.64 & 0.33 & 0.25 & 0.42 & 0.27 \\
\hline MgO & 0.37 & 0.40 & 0.35 & 0.29 & 0.41 & 0.28 & 0.11 & 0.32 & 0.41 \\
\hline MnO & 0.03 & 0.02 & 0.02 & 0.03 & 0.03 & 0.03 & 0.00 & 0.03 & 0.03 \\
\hline $\mathrm{K} 2 \mathrm{O}$ & 5.98 & 7.28 & 5.79 & 5.96 & 6.59 & 5.78 & 6.52 & 6.17 & 6.34 \\
\hline $\mathrm{Na2O}$ & 3.50 & 3.48 & 3.29 & 2.71 & 4.25 & 3.52 & 3.17 & 3.69 & 3.60 \\
\hline P2O5 & 0.09 & 0.03 & 0.05 & 0.07 & 0.08 & 0.10 & 0.12 & 0.07 & 0.11 \\
\hline Cr2O3 & 0.00 & 0.00 & 0.00 & 0.00 & 0.01 & 0.00 & 0.01 & 0.00 & 0.00 \\
\hline LOI & 0.92 & 0.87 & 1.20 & 1.80 & 0.42 & 0.72 & 0.80 & 0.68 & 0.70 \\
\hline Total & 100.27 & 99.48 & 100.93 & 101.74 & 99.13 & 98.15 & 101.75 & 99.03 & 101.45 \\
\hline \multicolumn{10}{|c|}{ Norma CIPW } \\
\hline $\mathbf{Q}$ & 25.762 & 20.76 & 29.53 & 31.783 & 17.303 & 27.76 & 32.594 & 24.653 & 25.741 \\
\hline C & 1.82 & 1.372 & 2.546 & 3.538 & 0.206 & 1.46 & 0.624 & 0.756 & 2.18 \\
\hline Or & 35.57 & 43.643 & 34.311 & 35.251 & 39.453 & 35.062 & 38.176 & 37.083 & 37.189 \\
\hline $\mathbf{A b}$ & 29.81 & 29.87 & 27.915 & 22.948 & 36.436 & 30.572 & 26.578 & 31.757 & 30.242 \\
\hline An & 2.501 & 1.114 & 2.412 & 2.772 & 2.686 & 1.009 & 0.453 & 1.655 & 0.617 \\
\hline Hy(MS) & 0.927 & 1.011 & 0.874 & 0.722 & & & 0.271 & & 1.014 \\
\hline Hy(FS) & 2.488 & 1.693 & 1.736 & 2.198 & 2.159 & 2.505 & 0.8 & 2.435 & 2.167 \\
\hline Mt & 0.431 & 0.275 & 0.293 & 0.36 & 0.344 & 0.406 & 0.133 & 0.399 & 0.352 \\
\hline II & 0.479 & 0.192 & 0.266 & 0.266 & 0.192 & 0.274 & 0. & 0.291 & 0.245 \\
\hline Ap & 0.211 & 0.07 & 0.116 & 0.162 & 0.188 & 0.239 & 0.276 & 0.164 & 0.253 \\
\hline \multicolumn{10}{|c|}{ Elem. traços } \\
\hline $\mathbf{R b}$ & 419.70 & 209.50 & 193.20 & 233.10 & 224.70 & 343.50 & 283.40 & 262.50 & 260.30 \\
\hline $\mathrm{Sr}$ & 67.00 & 121.00 & 74.00 & 76.00 & 95.00 & 48.00 & 50.00 & 65.00 & 69.00 \\
\hline $\mathrm{Ba}$ & 413.00 & 747.00 & 443.00 & 522.00 & 589.00 & 305.00 & 303.00 & 401.00 & 397.00 \\
\hline Nb & 26.81 & 4.35 & 7.93 & 12.52 & 7.53 & 27.05 & 9.29 & 16.50 & 13.75 \\
\hline $\mathbf{Y}$ & 63.00 & 31.00 & & & & & & & 50.00 \\
\hline $\mathrm{Ta}$ & 2.95 & 1.04 & 1.43 & 1.57 & 1.56 & 4.84 & & 2.10 & 2.02 \\
\hline $\mathrm{Zr}$ & 203.00 & 100.00 & 121.00 & 131.00 & 120.00 & 111.00 & 42.00 & 114.00 & 110.00 \\
\hline Sn & 5.70 & 0.70 & 1.50 & 2.70 & 2.60 & 12.20 & 3.90 & 6.60 & 9.40 \\
\hline $\mathrm{Hf}$ & 6.59 & 3.84 & 4.24 & 4.87 & 4.09 & 4.16 & 1.70 & 3.69 & 3.79 \\
\hline $\mathbf{N i}$ & 7.00 & 6.00 & 7.00 & 12.00 & 6.00 & 11.00 & 6.00 & 6.00 & 17.00 \\
\hline Th & 60.10 & 27.30 & 21.00 & 22.00 & 21.00 & 26.80 & 23.60 & 21.10 & 22.30 \\
\hline$U$ & 16.76 & 11.83 & 4.16 & 32.58 & 68.51 & 17.81 & 44.36 & 20.79 & 19.94 \\
\hline \multicolumn{10}{|c|}{ Terras Raras } \\
\hline La & 99.50 & 57.00 & 36.30 & 39.90 & 44.00 & 34.60 & & 36.90 & 29.80 \\
\hline $\mathrm{Ce}$ & 179.20 & 111.20 & 73.20 & 76.00 & 73.70 & 74.00 & 60.80 & 69.40 & 61.30 \\
\hline $\mathrm{Pr}$ & 21.89 & 13.18 & 7.52 & 9.22 & 9.24 & 8.16 & 6.32 & 8.19 & 6.75 \\
\hline Nd & 72.20 & 42.10 & 27.50 & 33.60 & 30.70 & 27.10 & & 25.60 & 21.80 \\
\hline Sm & 14.20 & 8.60 & 6.70 & 8.70 & 6.80 & 6.40 & 6.60 & 5.60 & 5.10 \\
\hline Eu & 0.72 & 1.02 & 0.70 & 0.98 & 1.04 & 0.51 & 0.50 & 0.60 & 0.54 \\
\hline Gd & 13.97 & 7.26 & 5.78 & 8.34 & 8.11 & 6.83 & 8.52 & 6.16 & 5.16 \\
\hline Tb & 2.23 & 1.15 & 1.11 & 1.57 & 1.53 & 1.28 & 2.24 & 1.17 & 1.01 \\
\hline Dy & 11.86 & 6.88 & 6.99 & 11.29 & 10.80 & 8.88 & 14.75 & 7.94 & 7.36 \\
\hline Ho & 2.29 & 1.42 & 1.33 & 2.54 & 2.40 & 1.86 & 2.90 & 1.74 & 1.57 \\
\hline $\mathrm{Er}$ & 7.40 & 3.99 & 4.18 & 8.20 & 8.42 & 6.28 & 8.00 & 4.93 & 5.40 \\
\hline $\mathrm{Tm}$ & 0.96 & 0.59 & 0.70 & 1.33 & 1.36 & 0.93 & 1.27 & 0.76 & 0.91 \\
\hline $\mathrm{Yb}$ & 6.20 & 5.30 & 4.80 & 10.30 & 9.10 & 6.20 & 7.00 & 5.70 & 5.30 \\
\hline Lu & 0.62 & 0.51 & 0.53 & 1.62 & 1.16 & 0.77 & 0.86 & 0.57 & 0.79 \\
\hline
\end{tabular}




\section{LITOGEOQUÍMICA DO LEUCOGRANITO}

A tabela 2 apresenta os dados analíticos de elementos maiores (\% em peso), traços e terrasraras (ppm) das 9 amostras do leucogranito de Gouveia. Nela estão também apresentados os seus respectivos dados da norma CIPW.

Os dados (\% em peso) de elementos maiores mostram que o leucogranito possui entre 70 e $77 \%$ de $\mathrm{SiO}_{2}$, entre 13 e $16 \%$ de $\mathrm{Al}_{2} \mathrm{O}_{3}$, FeOT menor que $2 \%$ e $\mathrm{CaO}$ e $\mathrm{MgO}$ abaixo de $0,7 \%$ cada. São ricos em potássio $\left(\mathrm{K}_{2} \mathrm{O}\right.$ entre 5 e $\left.7 \%\right)$ e sódio $\left(\mathrm{Na}_{2} \mathrm{O}\right.$ atinge até $4 \%$ ). No diagrama normativo Ab-An-Or (Figura 5B) são confirmados como granito. São rochas peraluminosas de acordo com o diagrama ACNKANK (Figura 5C), feição corroborada pela presença de coríndon normativo em todas as amostras estudadas. De acordo com o diagrama MALI versus sílica (Figura 5D), variam de rochas alcalinas a álcalicálcicas. Sua elevada razão $\mathrm{K} / \mathrm{Na}$, alto teor de $\mathrm{SiO}_{2}$ e baixos conteúdos de $\mathrm{Ca}$ (e $\mathrm{Sr}$ ), associados ao seu caráter peraluminoso e à presença de biotita e muscovita primárias, permitem chamá-los de tipo $\mathrm{S}$ na classificação de Chappell e White (1992), ou seja, resultantes de anatexia de material crustal essencialmente paraderivado.

O diagrama de elementos terras-raras normalizados ao condrito (Figura 6A) mostra padrão de similaridade das amostras entre si e destas com os leucogranitos peraluminosos colisionais

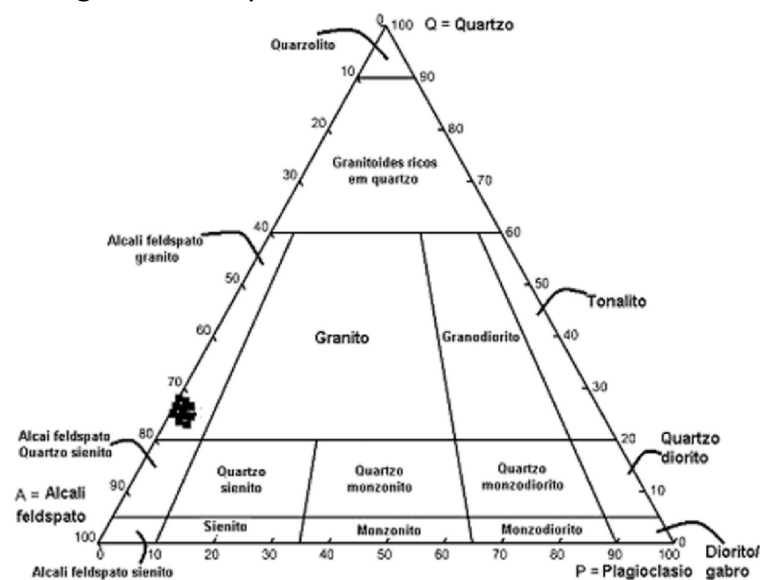

A

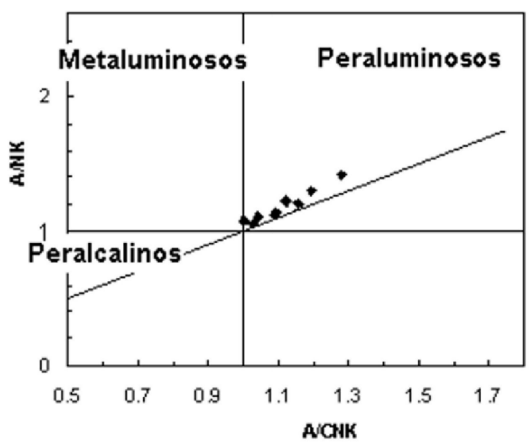

C
Himalaianos e Hercinianos. O leucogranito de Gouveia guarda um forte fracionamento entre terras-raras leves (ETRL) e pesadas (ETRP). Isto deve significar que minerais portadores de ETRP (p.ex. granada), não sofreram fusão durante a anatexia crustal geradora do leucogranito, ao contrário daqueles portadores de ETRL, os quais viriam a se alojar nos raros cristais de monazita do leucogranito. Minerais cálcicos do protólito (p.ex. plagioclásio anortítico) também não teriam sido anateticamente fundidos, o que resultaria na forte anomalia negativa de Eu verificada na figura $6 \mathrm{~A}$. Este fato parece ser confirmado pelo diagrama de elementos incompatíveis normalizados ao condrito (Figura 6B), no qual o $\mathrm{Sr}$, o $\mathrm{Rb}$ e o $\mathrm{Ba}$, elementos que juntamente com o Eu acompanham o $\mathrm{Ca}$, encontram-se como anomalias negativas. Minerais portadores de $\mathrm{Nb}$ e $\mathrm{Ta}$, como a ilmenita, também não teriam sido anateticamente fundidos a partir do protólito, já que do mesmo modo esses elementos apresentam-se como anomalias negativas nesta figura. Acrescentese a não-fusão de apatita e titanita/rutilo a partir da fonte, pois os elementos $P$ e Ti também se apresentam em pronunciada anomalia negativa na figura 6B. Estes últimos minerais não são encontrados no leucogranito (o teor de $\mathrm{P}_{2} \mathrm{O}_{5}$ e $\mathrm{TiO}_{2}$ está apenas ao redor de $0,1 \%$ cada). Merece destaque a pronunciada anomalia positiva de urânio apresentada pelo leucogranito de Gouveia (Figura 6B), anomalia esta já evidenciada na imagem gamaespectrométrica da figura 3.

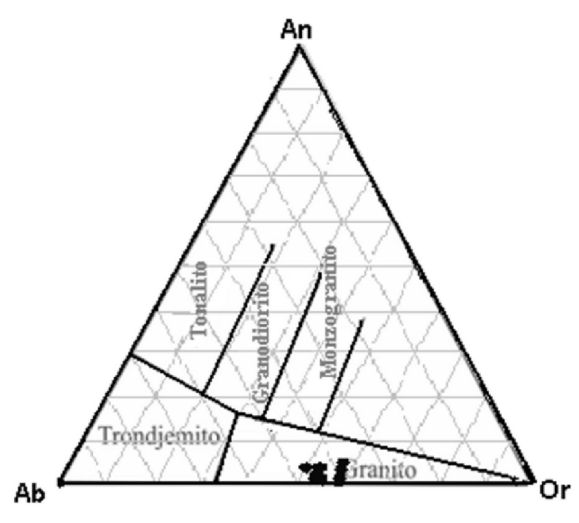

B

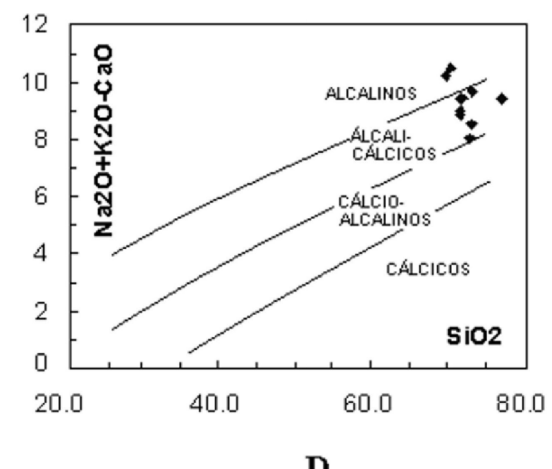

D

Figura 5 - (A) Diagrama modal QAP (Streckeisen, 1974). (B) Diagrama normativo Ab-An-Or (Barker, 1979). (C) Diagrama ACNK-ANK (Maniar e Piccoli, 1989). (D) Diagrama MALI x sílica (Frost, 2001). 


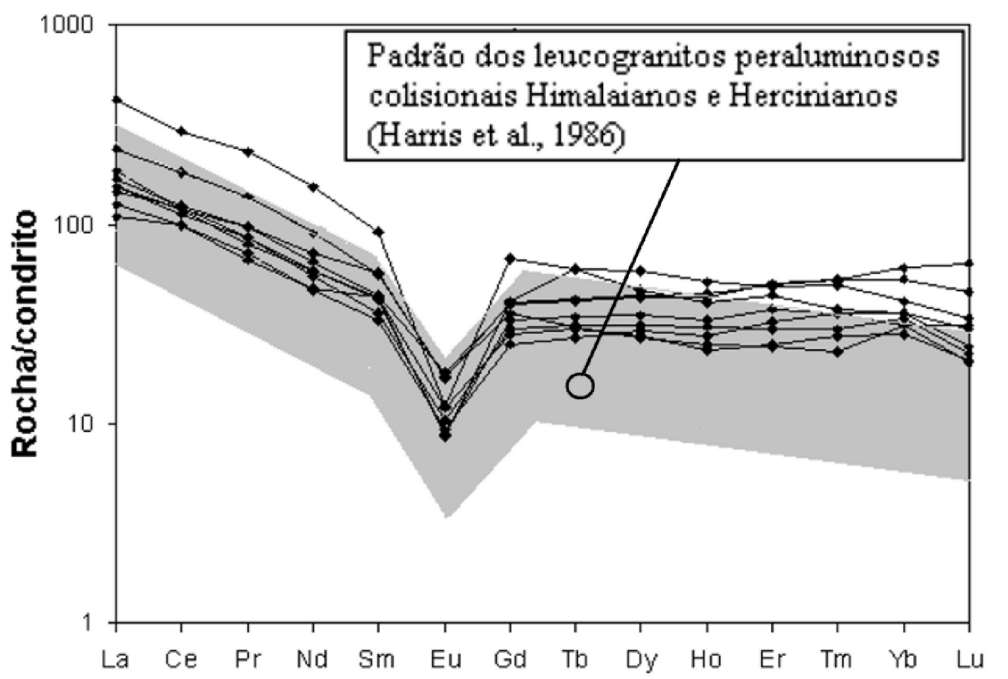

A
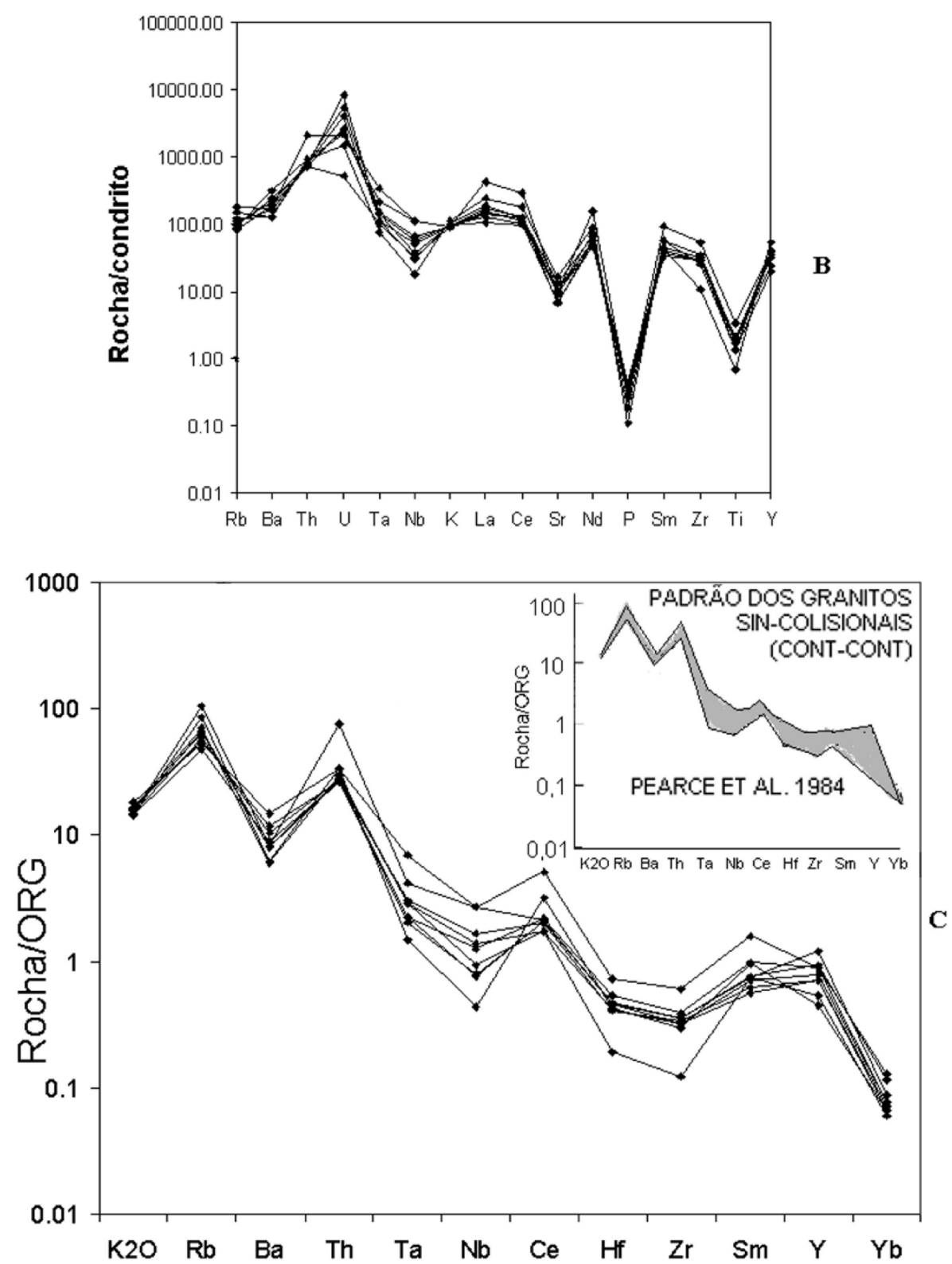

Figura 6 - Aracnogramas de elementos terras-raras (A) e de elementos incompatíveis (B) normalizados ao condrito (normalização segundo Sun \& MacDonough, 1989). Em (C) estão os elementos incompatíveis normalizados aos granitos de cadeia oceânica (ORG) de Pearce et al. (1984). o padrão dos granitos sin-colisionais (colisão continente-continente) deste último autor está apresentado para comparação com o leucogranito de Gouveia. 
Em termos tectônicos, segundo os diagramas R1R2 (Figura 7A), Hf-Rb/30-Tax3 (Figura 7B) e SiO2-Ta (Figura 7C), o leucogranito de Gouveia se classifica como sin- a tardi-colisional. Esta característica é reforçada pelo aracnograma de elementos incompatíveis normalizados aos granitos de cadeia oceânica (Figura 6C). O padrão do leucogranito de Gouveia é similar ao dos granitos sin-colisionais (colisão continente-continente) de Pearce et al. (1984), o que revela que a anatexia crustal se deu em função do espessamento crustal e cisalhamentos regionais associados, durante ou logo após o clímax de um evento de colisão de massas continentais, podendo eventualmente estar relacionada à tectônica transcorrente vinculada.

\section{DATAÇÃO QUÍMICA U-TH-PB DE MONAZITA DO LEUCOGRANITO}

$\mathrm{O}$ método de datação química $\mathrm{U}-\mathrm{Th}-\mathrm{Pb}$ (nãoisotópica) de monazita por microssonda eletrônica vem sendo desenvolvido há pelo menos 20 anos e já tem o reconhecimento da comunidade geológica por apresentar resultados que se equivalem à geocronologia isotópica U-Pb (Suzuki e Adachi, 1991; Williams et al., 2007). Cristais de monazita encontrados nas amostras 1, 11, 14, 22 (respectivamente grãos G1, G2, G3 e G4 da Figura 8, inclusos em K-feldspato do leucogranito) e 26 (grão G5 da Figura 9, incluso em K-feldspato dos turmalinitos tardios) foram quantitativamente analisados em microssonda eletrônica (Tabelas 3 e 4). Todos eles podem ser classificadas como monazitas de $\mathrm{Ce}$, porém os teores de $\mathrm{Y}, \mathrm{U}$ e $\mathrm{Pb}$ são bem menores no grão G5 quando comparados aos demais. Alguns grãos apresentaram sobrecrescimento de allanita, sendo que em algumas lâminas ela foi arrancada durante o polimento da preparação para análise. Todos os cristais de monazita estudados se mostraram internamente homogêneos, sem feições de zoneamento ou de recristalizações, nas imagens de elétrons retro-espalhados.
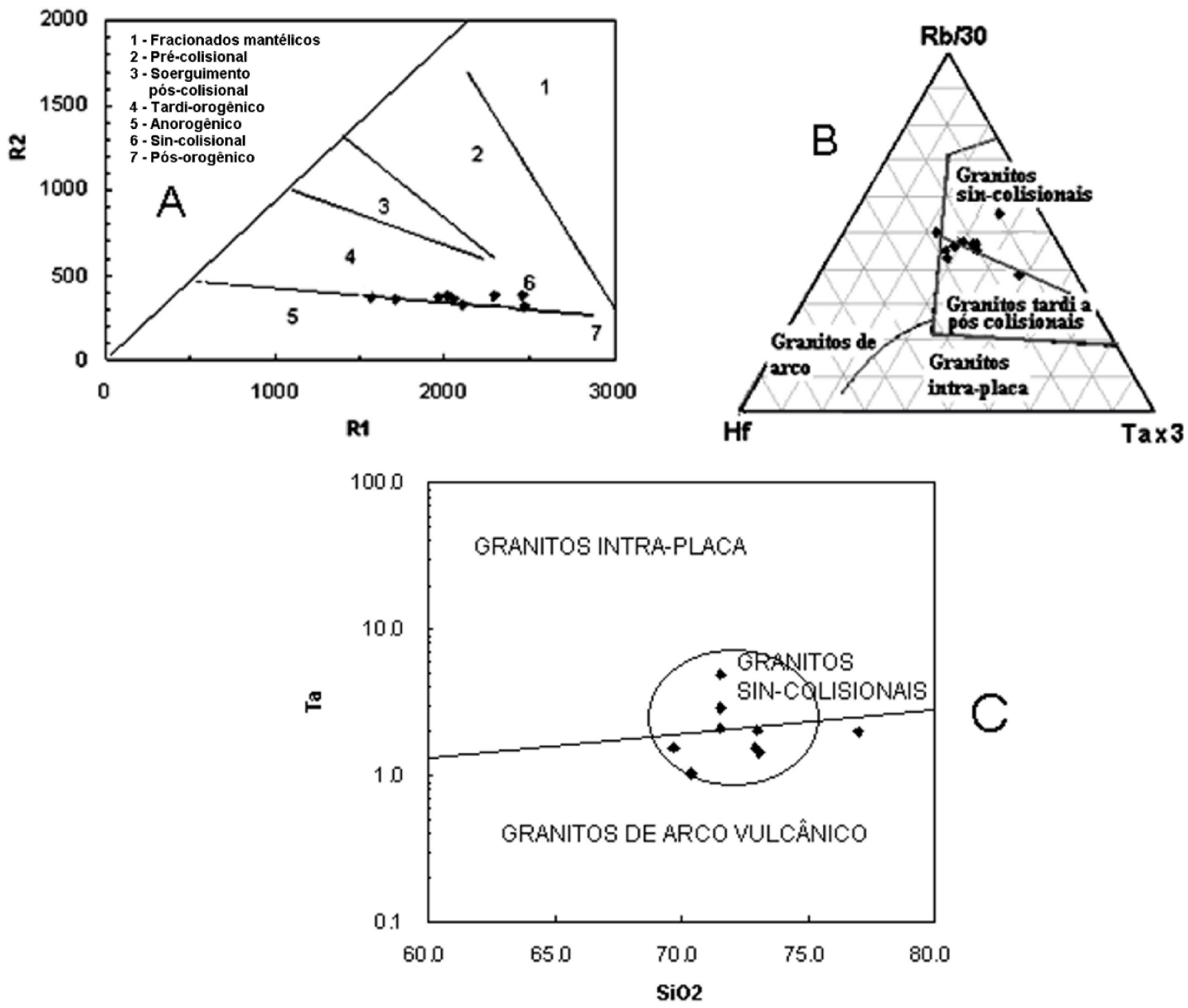

Figura 7 - (A) Diagrama multicatiônico R1-R2 (Batchelor \& Bowden, 1985). (B) Diagrama Hf-Rb/30-Tax3 (Harris et al., 1986). (C) Diagrama SiO2-Ta (Pearce et al., 1984). 
Nos grãos G1, G2, G3 e G4 foram feitas 5 análises em cada um deles e no grão G5 foram feitas 4 análises (Tabelas 3 e 4), em todos contemplando as regiões de centro e borda dos cristais. Nas tabelas 5 e 6 encontram-se os valores das idades calculados com o auxílio do software EPMA Dating (Pommier et al., 2004). As médias das idades de cada grão, obtidas com o apoio do software Isoplot (Ludwig, 2003), são apresentadas na figura 10.

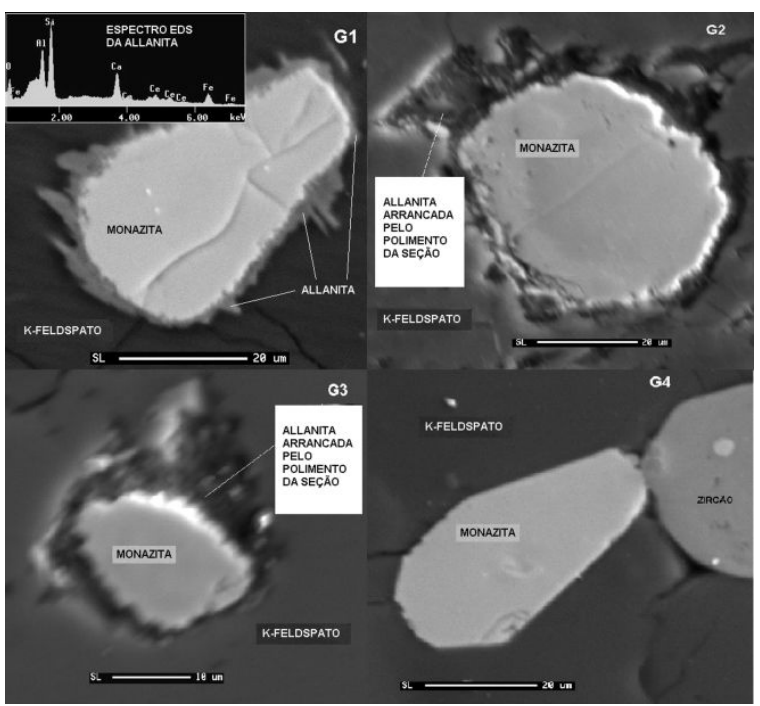

Figura 8 - Cristais de monazita G1, G2, G3 e G4 em imagens de elétrons retro-espalhados obtidas na microssonda eletrônica.

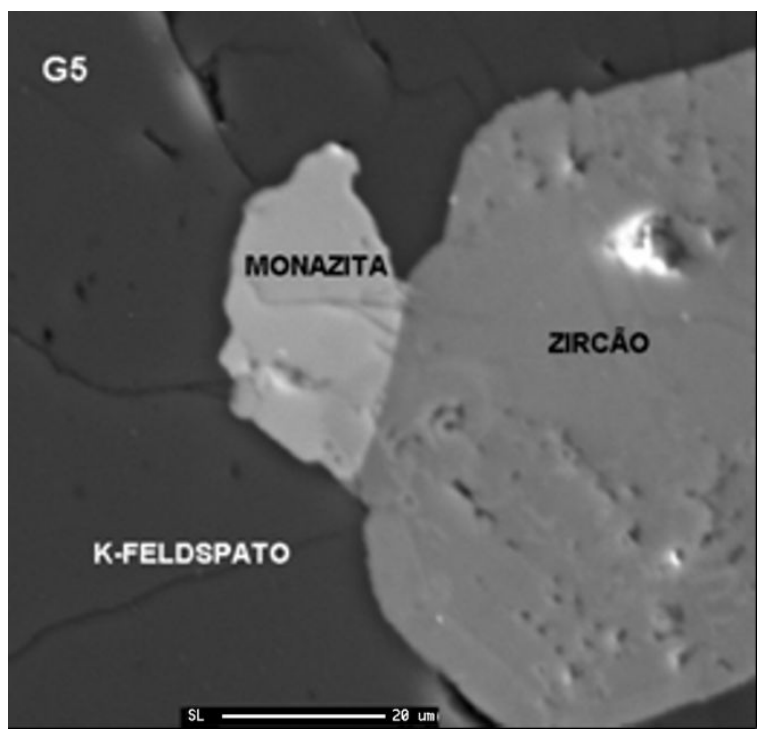

Figura 9 - Cristal de monazita G5 em imagem de elétrons retroespalhados obtida na microssonda eletrônica.

Finalmente, analisando os dados de U-Th-Pb em cristais de monazita inclusos em cristais de Kfeldspato, é possível inferir que a idade média para os grãos G1, G2, G3 e G4 de 1811 +/- 32 Ma seja a idade de cristalização magmática do leucogranito de Gouveia (tabela 7). Já a idade de 634 +/- 20 Ma para o grão G5 encontrado nos turmalinitos tardios pode ser proveniente de processos Brasilianos de remobilização e turmalinização do leucogranito. Esta turmalinização é certamente mais recente que os quartzitos do Supergrupo Espinhaço, já que os turmalinitos guardam clastos destas rochas em seu interior.

Tabela 3 - Composições químicas dos grãos de monazita G1, G2, G3 e G4 obtidas em microssonda eletrônica.

\begin{tabular}{|c|c|c|c|c|c|c|c|c|c|c|c|c|c|c|c|c|}
\hline Monazita & Y2O3 & Dy203 & P2O5 & $\mathrm{SiO} 2$ & $\mathrm{Gd} 2 \mathrm{O} 3$ & $\mathrm{PbO}$ & ThO2 & $\mathrm{Sm} 2 \mathrm{O} 3$ & UO2 & $\mathrm{MnO}$ & $\mathrm{CaO}$ & $\mathrm{Nd} 2 \mathrm{O} 3$ & La2O3 & Pr2O3 & Ce2O3 & Total \\
\hline G1-1 & 4.77 & 1.15 & 28.70 & 1.38 & 2.09 & 1.18 & 10.62 & 2.47 & 1.30 & 0.04 & 2.05 & 9.26 & 9.33 & 2.57 & 23.77 & 100.67 \\
\hline G1-2 & 4.06 & 1.10 & 28.63 & 1.12 & 2.00 & 1.39 & 10.56 & 2.37 & 2.05 & 0.01 & 2.40 & 9.30 & 9.47 & 2.59 & 23.87 & 100.91 \\
\hline G1-3 & 2.75 & 1.00 & 29.27 & 0.92 & 1.61 & 1.19 & 11.82 & 2.43 & 0.98 & 0.02 & 2.54 & 9.58 & 10.08 & 2.48 & 24.88 & 101.53 \\
\hline G1-4 & 4.68 & 1.25 & 27.90 & 1.56 & 2.13 & 1.54 & 13.34 & 2.47 & 1.75 & 0.04 & 2.62 & 9.17 & 7.88 & 2.36 & 20.75 & 99.45 \\
\hline G1-5 & 4.96 & 1.47 & 27.74 & 1.79 & 2.19 & 1.63 & 13.92 & 2.42 & 1.92 & 0.02 & 2.54 & 9.04 & 7.41 & 2.20 & 20.67 & 99.91 \\
\hline G2-1 & 5.14 & 1.31 & 27.87 & 1.72 & 2.39 & 1.73 & 14.17 & 2.57 & 2.02 & 0.01 & 2.70 & 9.14 & 7.01 & 2.26 & 19.72 & 99.75 \\
\hline G2-2 & 5.18 & 1.40 & 27.94 & 1.71 & 2.21 & 1.70 & 13.66 & 2.65 & 2.07 & 0.03 & 2.61 & 8.93 & 7.23 & 2.50 & 20.37 & 100.19 \\
\hline G2-3 & 5.01 & 1.22 & 27.81 & 1.88 & 2.27 & 1.64 & 13.54 & 2.52 & 1.91 & 0.02 & 2.64 & 8.76 & 7.53 & 2.38 & 21.27 & 100.39 \\
\hline G2-4 & 4.97 & 1.32 & 28.01 & 1.85 & 2.39 & 1.74 & 14.06 & 2.48 & 2.08 & 0.03 & 2.67 & 9.19 & 7.17 & 2.26 & 20.54 & 100.76 \\
\hline G2-5 & 3.43 & 1.02 & 29.59 & 1.12 & 1.88 & 1.38 & 10.23 & 2.29 & 1.87 & 0.02 & 3.42 & 9.13 & 9.61 & 2.45 & 23.71 & 101.14 \\
\hline G3-1 & 3.28 & 0.95 & 29.89 & 1.06 & 1.78 & 1.08 & 9.53 & 2.08 & 1.24 & 0.02 & 2.03 & 9.46 & 10.78 & 2.52 & 25.45 & 101.16 \\
\hline G3-2 & 4.80 & 1.15 & 29.91 & 1.35 & 1.93 & 1.33 & 10.15 & 2.49 & 1.82 & 0.01 & 2.27 & 9.35 & 9.02 & 2.58 & 23.47 & 101.63 \\
\hline G3-3 & 3.40 & 1.06 & 28.76 & 1.05 & 1.86 & 1.32 & 10.16 & 2.26 & 1.84 & 0.03 & 2.36 & 9.39 & 9.69 & 2.60 & 24.91 & 100.67 \\
\hline G3-4 & 4.52 & 1.27 & 27.54 & 1.40 & 1.98 & 1.34 & 10.86 & 2.26 & 1.74 & 0.02 & 2.21 & 9.66 & 8.96 & 2.40 & 23.22 & 99.37 \\
\hline G3-5 & 4.54 & 1.27 & 27.56 & 1.38 & 1.97 & 1.21 & 9.88 & 2.23 & 1.54 & 0.03 & 1.85 & 9.33 & 9.60 & 2.40 & 23.62 & 98.41 \\
\hline G4-1 & 4.26 & 1.04 & 27.81 & 1.36 & 1.94 & 1.28 & 10.03 & 2.29 & 1.66 & 0.01 & 1.93 & 9.71 & 9.72 & 2.30 & 23.62 & 98.94 \\
\hline G4-2 & 4.30 & 1.09 & 28.16 & 1.39 & 1.92 & 1.32 & 10.02 & 2.29 & 1.79 & 0.03 & 2.10 & 9.54 & 9.61 & 2.22 & 23.62 & 99.37 \\
\hline G4-3 & 4.33 & 1.05 & 27.67 & 1.45 & 1.85 & 1.26 & 10.14 & 2.28 & 1.65 & 0.01 & 1.91 & 9.82 & 9.58 & 2.20 & 22.98 & 98.18 \\
\hline G4-4 & 4.31 & 1.12 & 28.11 & 1.27 & 1.94 & 1.32 & 9.92 & 2.11 & 1.80 & 0.01 & 2.09 & 9.27 & 9.71 & 2.27 & 22.89 & 98.15 \\
\hline G4-5 & 4.15 & 1.13 & 28.21 & 1.42 & 1.96 & 1.33 & 10.03 & 1.99 & 1.89 & 0.02 & 2.12 & 9.22 & 9.87 & 2.35 & 23.69 & 99.40 \\
\hline
\end{tabular}

Tabela 4 - Composição química do grão de monazita G5 obtida em microssonda eletrônica.

\begin{tabular}{|c|c|c|c|c|c|c|c|c|c|c|c|c|c|c|c|c|}
\hline Monazita & Y2O3 & Dy203 & P2O5 & $\mathrm{SiO} 2$ & $\mathrm{Gd} 2 \mathrm{O} 3$ & $\mathrm{PbO}$ & ThO2 & $\mathrm{Sm} 2 \mathrm{O} 3$ & UO2 & $\mathrm{MnO}$ & $\mathrm{CaO}$ & $\mathrm{Nd} 2 \mathrm{O} 3$ & La2O3 & Pr2O3 & $\mathrm{Ce} 2 \mathrm{O} 3$ & Total \\
\hline G5-1 & 0.98 & 0.58 & 27.11 & 0.90 & 1.94 & 0.30 & 10.26 & 2.77 & 0.41 & 0.03 & 2.47 & 11.05 & 10.29 & 2.97 & 26.06 & 98.0 \\
\hline G5-2 & 0.69 & 0.47 & 28.95 & 0.95 & 1.97 & 0.20 & 6.90 & 2.99 & 0.16 & 0.01 & 1.01 & 12.32 & 11.51 & 3.22 & 29.51 & 100.9 \\
\hline G5-3 & 0.76 & 0.43 & 27.82 & 0.92 & 1.88 & 0.24 & 7.19 & 2.82 & 0.49 & 0.02 & 1.49 & 11.92 & 11.24 & 2.97 & 29.55 & 99.7 \\
\hline G5-4 & 0.72 & 0.54 & 27.98 & 1.17 & 1.84 & 0.31 & 10.62 & 2.73 & 0.24 & 0.03 & 1.64 & 10.99 & 10.85 & 2.91 & 28.65 & 101.2 \\
\hline
\end{tabular}


Tabela 5- Idades químicas U-Th-Pb dos cristais de monazita G1, G2, G3 e G4 e respectivos erros analíticos de U, Th e Pb.

\begin{tabular}{|c|c|c|c|c|c|c|c|c|c|c|c|c|}
\hline $\begin{array}{l}\text { Monazita } \\
\text {-análise }\end{array}$ & $\begin{array}{c}\text { Idade } \\
\text { Ma }\end{array}$ & $\begin{array}{c}\text { Erro } \\
\text { Idade } \\
\mathrm{Ma}\end{array}$ & $\begin{array}{c}\mathrm{U} \\
\mathrm{ppm}\end{array}$ & $\begin{array}{c}\text { Erro } \\
\text { U } \\
\%\end{array}$ & $\begin{array}{c}\text { Erro } \\
U \\
\mathrm{ppm}\end{array}$ & $\begin{array}{c}\text { Th } \\
\mathrm{ppm}\end{array}$ & $\begin{array}{c}\text { Erro } \\
\text { Th } \\
\%\end{array}$ & $\begin{array}{c}\text { Erro } \\
\text { Th } \\
\text { ppm }\end{array}$ & $\begin{array}{c}\mathrm{Pb} \\
\mathrm{ppm}\end{array}$ & $\begin{array}{c}\text { Erro } \\
\mathrm{Pb} \\
\%\end{array}$ & $\begin{array}{c}\text { Erro } \\
\mathrm{Pb} \\
\mathrm{ppm}\end{array}$ & $\mathrm{MPb}$ \\
\hline $1-1$ & 1771 & 71 & 10892 & 2.00 & 218 & 93329 & 2.00 & 1867 & 10945 & 2.00 & 219 & 20740 \\
\hline $1-2$ & 1774 & 71 & 7507 & 2.00 & 350 & 92801 & 2.00 & 1856 & 12922 & 2.00 & 258 & 07.198 \\
\hline $1-3$ & 793 & 72 & 2019 & .00 & 159 & 103848 & 2.00 & 077 & 11065 & 2.00 & 221 & \\
\hline $1-4$ & 802 & 72 & 4645 & 2.00 & 293 & 117249 & 2.00 & 2345 & 14314 & 2.00 & 286 & 207.377 \\
\hline $1-5$ & 799 & 72 & 5129 & 2.00 & 323 & 122329 & 2.00 & 2447 & 15168 & 2.00 & 303 & 07.355 \\
\hline $2-1$ & 1843 & & & & 341 & & 2.00 & 2490 & & 2.00 & 321 & \\
\hline $2-2$ & 844 & 74 & 7447 & 2.00 & 349 & 120079 & 2.00 & 2402 & 15818 & 2.00 & 316 & 207.312 \\
\hline $52-3$ & 836 & & 6079 & 2.00 & 322 & 118972 & 2.00 & 2379 & 15215 & 2.00 & 304 & \\
\hline $2-4$ & 1843 & 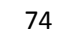 & 7566 & 2.00 & 351 & 123594 & 2.00 & 2472 & 16143 & 2.00 & 323 & 207.322 \\
\hline $2-5$ & 1846 & & 5930 & 2.00 & 319 & 89884 & 2.00 & 1798 & 12764 & 2.00 & 255 & 207.224 \\
\hline 3-1 & 778 & & 0424 & 2.00 & 208 & 83776 & 2.00 & 1676 & 10063 & 2.00 & 201 & 07.380 \\
\hline 33-2 & 1812 & 77 & 511 & 2.00 & 310 & 89181 & 2.00 & 1784 & 12309 & 2.00 & 246 & 207.234 \\
\hline $3-3$ & 799 & & & & 312 & & 2.00 & 1786 & & 2.00 & 245 & 231 \\
\hline $3-4$ & 1796 & & 4766 & 2.00 & 295 & 5403 & 2.00 & 1908 & 12476 & 2.00 & 250 & 207.286 \\
\hline G3-5 & 1794 & ב7 & 2987 & 2.00 & 260 & 86861 & 2.00 & 1737 & 11205 & 2.00 & 224 & 207.301 \\
\hline $4-1$ & 1820 & & 4072 & 2.00 & 281 & 88144 & 2.00 & 1763 & 11836 & 2.00 & 237 & 207.272 \\
\hline G4-2 & 1830 & 73 & 15183 & 2.00 & 304 & 88012 & 2.00 & 1760 & 12244 & 2.00 & 245 & 207.237 \\
\hline $4-3$ & 1799 & & 3969 & 2.00 & 279 & 89119 & 2.00 & 1782 & 11734 & 2.00 & 235 & 207.280 \\
\hline G4-4 & 1835 & 73 & 15321 & 2.00 & 306 & 87203 & 2.00 & 1744 & 12254 & 2.00 & 245 & 207.228 \\
\hline G4-5 & 1808 & 72 & 16108 & 2.00 & 322 & 88117 & 2.00 & 1762 & 12374 & 2.00 & 247 & 207.211 \\
\hline
\end{tabular}

Tabela 6 - Idades químicas U-Th-Pb do cristal de monazita G5 e respectivos erros analíticos de U, Th e Pb.

\begin{tabular}{|c|c|c|c|c|c|c|c|c|c|c|c|c|}
\hline $\begin{array}{l}\text { Monazita- } \\
\text { análise }\end{array}$ & $\begin{array}{c}\text { Idade } \\
\text { Ma }\end{array}$ & $\begin{array}{c}\text { Erro } \\
\text { Idade } \\
\text { Ma }\end{array}$ & $\begin{array}{c}\mathrm{U} \\
\mathrm{ppm}\end{array}$ & $\begin{array}{c}\text { Erro } \\
\text { U } \\
\%\end{array}$ & $\begin{array}{c}\text { Erro } \\
\text { U } \\
\text { ppm }\end{array}$ & $\begin{array}{c}\text { Th } \\
\text { ppm }\end{array}$ & $\begin{array}{c}\text { Erro } \\
\text { Th } \\
\%\end{array}$ & $\begin{array}{c}\text { Erro } \\
\text { Th } \\
\text { ppm }\end{array}$ & $\begin{array}{c}\mathrm{Pb} \\
\mathrm{ppm}\end{array}$ & $\begin{array}{c}\text { Erro } \\
\mathrm{Pb} \\
\%\end{array}$ & $\begin{array}{c}\text { Erro } \\
\mathrm{Pb} \\
\text { ppm }\end{array}$ & $\mathrm{MPb}$ \\
\hline G5-1 & 614 & 35 & 3014 & 3.32 & 100 & 90191 & 2.00 & 1804 & 2766 & 3.61 & 100 & 207.784 \\
\hline G5-2 & 637 & 50 & 1016 & 9.85 & 100 & 60646 & 2.00 & 1213 & 1838 & 5.44 & 100 & 207.875 \\
\hline G5-3 & 657 & 43 & 3926 & 2.55 & 100 & 63159 & 2.00 & 1263 & 2256 & 4.43 & 100 & 207.645 \\
\hline G5-4 & 638 & 37 & 1548 & 6.46 & 100 & 93364 & 2.00 & 1867 & 2831 & 3.53 & 100 & 207.876 \\
\hline
\end{tabular}
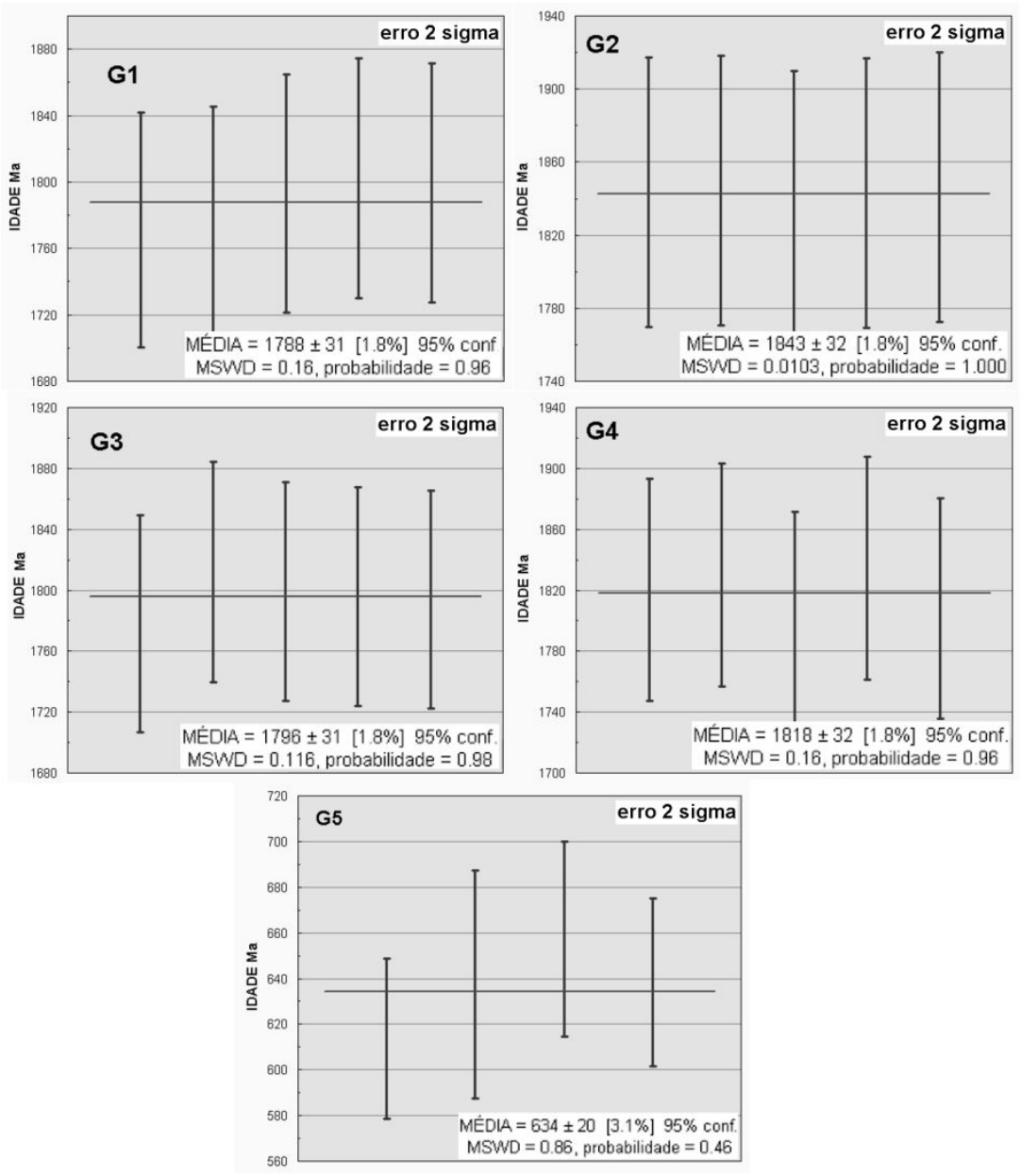

Figura 10 - Valores médios de idade dos grãos de monazita estudados. 
Tabela 7 - Resultados finais das idades dos cristais de monazita.

\begin{tabular}{|c|c|c|cc|}
\hline Monazita & $\begin{array}{c}\text { Idade } \\
\text { Ma }\end{array}$ & $\begin{array}{c}\text { Erro } \\
\text { Idade } \\
\text { Ma }\end{array}$ & $\begin{array}{c}\text { Média dos } \\
\text { Idade }\end{array}$ & $\begin{array}{c}\text { cristais G1, G2, G3 e G4 } \\
\text { Erro } \\
\text { Idade }\end{array}$ \\
G1 & 1788 & 31 & Ma & Ma \\
G2 & 1843 & 32 & $\mathbf{1 8 1 1}$ & $\mathbf{3 2}$ \\
G3 & 1796 & 31 & & \\
G4 & 1818 & 32 & & \\
\hline G5 & $\mathbf{6 3 4}$ & $\mathbf{2 0}$ & \\
\hline
\end{tabular}

\section{DISCUSSÕES E CONCLUSÕES}

Um possível modelo petrogenético para granitos peraluminosos é extraído de Barbarin (1996), segundo o qual resultados experimentais confirmam que os granitos ricos em muscovita (MPG), também chamados de granitos a duas micas pela presença subordinada de biotita, cristalizam sob fugacidades de água mais elevadas que os granitos a cordierita (CPG). O conteúdo inicial de água no magma não ultrapassa os $4 \%$ para os granitos a cordierita, mas alcança 7 a $8 \%$ para permitir a precipitação de muscovita nos granitos a muscovita. A grande quantidade de água nestes magmas é fornecida por grandes zonas de cisalhamento ou empurrões que concentram e canalizam fluidos na crosta. Estes fluidos não apenas lubrificam as zonas de cisalhamento, mas também promovem extensa fusão. Os MPG são abundantes nos cinturões orogênicos Hercinianos, onde há abundantes zonas de cisalhamento transcorrentes e empurrões, bem como ao longo do Empurrão Principal Central dos Himalaias e são raros nos cinturões em que há poucas zonas de cisalhamento. Assim, a petrogênese dos granitos peraluminosos a duas micas acha-se intrinsecamente ligada ao controle estrutural regional.

Segundo Barbarin (1999), granitos peraluminosos acham-se fortemente associados a ambientes de colisão continental e tectônica transcorrente associada (tipos MPG e CPG da figura 11), granitos metaluminosos associam-se com zonas de convergência oceano-continente ou oceano-oceano (tipos KCG e ACG da figura 11), plagiogranitos (RTG da figura 11) são encontrados em ambientes de expansão oceânica e os granitos alcalinos e peralcalinos (PAG da figura 11) em zonas de rifteamento. A maior parte do Complexo de Gouveia é constituída por massas do leucogranito investigado, o qual se assemelha fortemente aos granitos peraluminosos com muscovita de Barbarin (1999), representados pelo tipo MPG colisional oriundo de fusão crustal da figura 11. Nesta figura é possível notar a semelhança mineralógica entre o leucogranito de Gouveia e o tipo MPG.

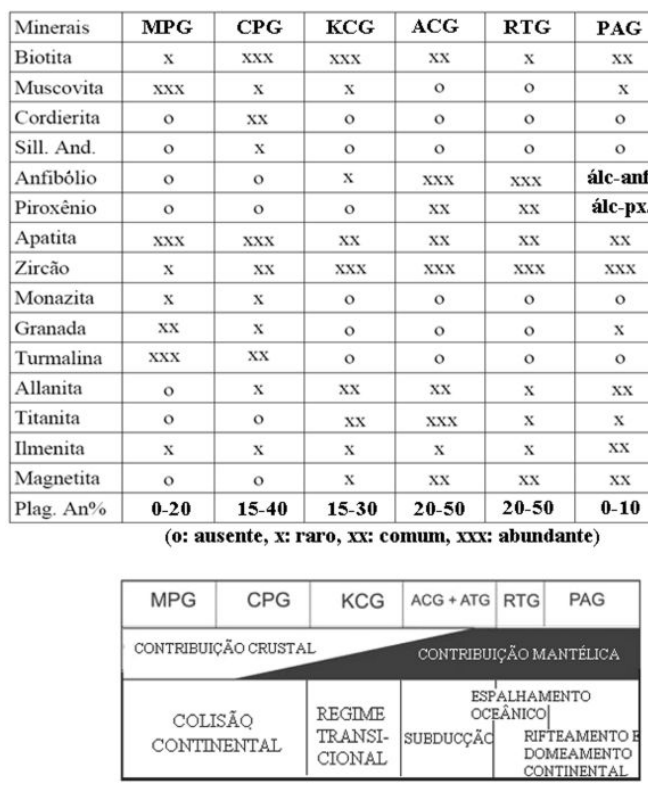

Figura 11 - Quadro mineralógico comparativo de granitos (MPG: granito peraluminoso a muscovita, CPG: granito peraluminoso a cordierita, KCG: granito e granodiorito cálcio-alcalino de alto-K, ACG: granito cálcio-alcalino com anfibólio, RTG: plagiogranito toleítico de cordilheira meso-oceânica, PAG: granito e sienito alcalino e peralcalino), e ao lado direito o leucogranito de Gouveia (LGG). Na porção inferior estão apresentados os aspectos da fonte dos granitos e do ambiente tectônico associado (Barbarin, 1999).

Em termos de idades, o valor encontrado de 1811 +/- $32 \mathrm{Ma}$ para o evento anatético e cristalização do magma leucogranítico de Gouveia é similar, dentro da margem de erro, ao valor da idade isotópica U-Pb em zircão de 1844 +/- $15 \mathrm{Ma}$ de Machado et al. (1989). A idade de $2839+/-14 \mathrm{Ma}$ também encontrada por estes últimos autores poderia ser atribuída a núcleos de zircões herdados do protólito migmatítico arqueano do leucogranito. Estes zircões não teriam sido fundidos totalmente na anatexia que gerou o leucogranito. A propósito, Silva et al. (2002) encontraram uma idade de $2867+/-10$ Ma para os gnaisses migmatíticos do vizinho Complexo Guanhães (Figura 2), praticamente a mesma idade do Complexo de Gouveia.

A relação geológica do leucogranito estudado a migmatitos, sua relação com zonas de cisalhamento e sua intensa milonitização sugerem que a anatexia que o gerou teria se dado em condições de alto-grau metamórfico (fácies anfibolito alto) em ambiente hidratado atingidas em função do espessamento crustal e cisalhamentos regionais devidos à colisão continental Transamazônica ou à tectônica transcorrente associada. Deste modo, a fusão parcial dos migmatitos peraluminosos locais teria de fato levado à formação do leucogranito de Gouveia a duas micas com granada. Restos de migmatitos paraderivados no seu interior em contato transicional difuso reforçam essa gênese. 
Rochas metabásicas de 906 Ma (Machado et al., 1989) alojadas no interior do leucogranito de Gouveia estão metamorfisadas devido ao evento tectonotermal Brasiliano (630 a $490 \mathrm{Ma}$, Dossin et al., 1993). Portanto, a influência deste evento sobre o leucogranito é inegável. Daí decorre a idade de 634 +/- 20 Ma da monazita encontrada em turmalinito tardio que cruza o leucogranito de Gouveia. O leucogranito teria sido levado às condições de pressão e temperatura do fácies xistoverde no Brasiliano, quando surgiu a clorita. A reação metamórfica entre biotita e quartzo que promoveu o surgimento da clorita no leucogranito, levou também ao aparecimento da magnetita (Yardley, 1994).

\section{AGRADECIMENTOS}

Ao Instituto Casa da Glória pelo apoio logístico durante os trabalhos de campo. À PRPq-UFMG pelo apoio financeiro concedido. Ao Laboratório de Microanálises do Depto. Física-UFMG, pelas análises da monazita, em especial aos Drs. Luiz Garcia e Abá Persiano.

\section{REFERÊNCIAS}

Barbarin B. 1996. Genesis of the two main types of peraluminous granitoids. Geology, 4: 95-298

Barbarin B., 1999. A review of the relationships between granitoid types, their origins and their geodynamic environments. Lithos 46 : 605-626

Barker, F., 1979. Trondhjemites: definitions, environment and hypotheses of origin. In: F Barker (eds.) Trondhjemites, dacites and related rocks. Amsterdam, Elsevier, p. 1-12.

Batchelor R.A. e Bowden P., 1985. Petrogenetic interpretation of granitoid rock series using multicationic parameters. Chemical Geology, 48:43-55.

Chappell, B.W., White, A.J.R. 1992. I- and S-type granites in the Lachlan Fold Belt. Transactions of the Royal Society of Edinburgh, Earth Sciences 83, 1-26.

CODEMIG. Cia. Desenvolvimento Economico de Minas Gerais. 2012. Programa de Levantamento Aerogeofísico de Minas Gerais - Magnetometria e gamaespectrometria.

Cruz, S. C. P.; Alkmim, F. F.; Lagoeiro, L. E. 2005. Zona de cisalhamento do núcleo do anticlinório de Gouveia, Cordilheira do Espinhaço, MG: geometria, cinemática e processos deformacionais. Revista Brasileira de Geociências, 35: $441-452$

Dossin, T.M.; Dossin, I.A.; Charvet, J.; Pouclet, A.; Lapierre, H. 1993. Late proterozoic mafic dykes swarm from the Espinhaço Range (Minas Gerais, Brazil): geochemistry and tectonic setting. In: SIMPÓSIO SOBRE O CRÁTON SÃO FRANCISCO, 2, Salvador, 1993. Anais. Salvador, p.128-130.

Frost, B. R., Barnes, C. G., Collns, W. J., Arculus, R. J., Ellis, D. J., \& Frost, C, D., 2001. A geochemical classification for granitic rocks. J. Petrology, 42, p. 2033 - 2048.

Harris N.B.W., Pearce J.A., \& Tindle A.G., 1986. Geochemical characteristics of collision-zone magmatism. In: Coward, $M$. P. \& Ries, A. C. (eds). Collision Tectonics. Geol. Soc. Spec. Pub, 19: $67-81$
Hoffmann C. 1983. The Archean peraluminous Gouveia Granite: its structures, geochemistry and phase petrology (Serra do Espinhaço, Minas Gerais, Brazil). N. Jb. Min., 2: 359-371.

Ludwig K.R. 2003. Isoplot/Ex 3.00: A geochronological toolkit for Microsoft Excel. Berkeley Geochronology Center, Special Publication, n.4, 70 p.

Machado N., Schrank A., Abreu F.R., Knauer L.G., Almeida-Abreu P.A., 1989. Resultados preliminares da geocronologia U-Pb na Serra do Espinhaço Meridional. In: SBG, Núcleo Minas Gerais, Boletim Informativo, 10: 171-174.

Maniar P.D. e Piccoli P.M., 1989. Tectonic discriminations of granitoids. Geological Socitey of America Bulletin, 101: 635643.

Noce C.M., Pedrosa-Soares A.C., Silva L.C., Alkmim F.F., 2007. O Embasamento Arqueano e Paleoproterozóico do Orógeno Araçuaí. Geonomos 15(1): 17 - 23

Pearce J.A., Harris N.B.W., Tindle A.G. 1984. Trace element discrimination diagrams for the tectonic interpretation of granitic rocks. J. Petrology, 25: 956-983.

Pedrosa-Soares A.C. e Soares-Filho B.S. (coordenadores e editores). 1997. Projeto Espinhaço em CD-ROM (textos, mapas e anexos). Belo Horizonte, COMIG - Companhia Mineradora de Minas Gerais.

Pedrosa-Soares A.C., Noce C.M., Wiedemann C.M., Pinto C.P., 2001. The Araçuaí-West Congo orogen in Brazil: An overview of a confined orogen formed during Gondwanland assembly. Precambrian Research, 110: 307-323.

Pommier A., Cocherie A., Legendre O. 2004. EPMA Dating User Manual, V.1.01: Age Calculation from Electron Probe Microanalyser Measurements of U-Th-Pb. BRGM, Orleans.

Scherrer N.C., Engi M., Gnos E., Jakob V., Liechti A. 2000. Monazite analysis; from sample preparation to microprobe age dating and REE quantification. Schweizer Mineralogische und Petrographische Mitteilungen, 80: 93-105.

Schöll W.U. e Fogaça A.C., 1979. Estratigrafia da Serra do Espinhaço na região de Diamantina. In: SBG, Simp. Geol. Minas Gerais, 1, Atas, p. 276-290.

Silva L.C., Armstrong R., Noce C.M, Carneiro M.A., Pimentel M.M., Pedrosa-Soares A.C., Leite C.A., Vieira V.S., Silva M.A., Paes V.J.C., Cardoso-Filho J.M. 2002. Reavaliação da evolução geológica em terrenos pré-cambrianos brasileiros com base em novos dados U-Pb SHRIMP, parte II: Orógeno Araçuaí, Cinturão Mineiro e Cráton São Francisco Meridional. Rev. Bras. Geociências, 32:513-528

Streckeisen A. L., 1974. Classification and Nomenclature of Plutonic Rocks. Recommendations of the IUGS Subcommission on the Systematics of Igneous Rocks. Geologische Rundschau. Internationale Zeitschrift für Geologie. Stuttgart. Vol.63, p.773-785.

Sun S. e Mcdonough W. 1989. Chemical and isotopic systematics of oceanic basalts: implications for mantle composition and processes. In: Saunders, A.D. \& Norry, M.J. (editors), Magmatism in the Ocean Basins. London. Geological Society Special Publication, , p.313-345.

Suzuki K. e Adachi M., 1991. Precambrian provenance and Silurian metamorphism of the Tsubonosawa paragneiss in the South Kitakami terrane, Northeast Japan, revealed by the chemical Th-U-total $\mathrm{Pb}$ isochron ages of monazite, zircon, and xenotime. Geochemical Journal. 25: 357- 376.

Uhlein A., 1991. Transição craton-faixa dobrada: um exemplo do Cráton do São Francisco e da Faixa Araçuaí (Ciclo Brasiliano) no Estado de Minas Gerais: Aspectos estratigráficos e estruturais. São Paulo, IG-USP, Tese de Doutorado. 
Williams ML, Jercinovic MJ, Hetherington CJ. 2007. Microprobe monazite geochronology: understanding geologic processes by integrating composition and chronology. Ann Review Earth Planetary Sciences. 35: 137-175.
Yardley, B. W. D., 1994. Introdução a petrologia metamórfica; traduzido por R. Fuck.- editora UnB. 340 p. 